Discussion Paper No. 09-077

\title{
Social Preferences under Risk - An Experimental Analysis
}

Christiane Bradler

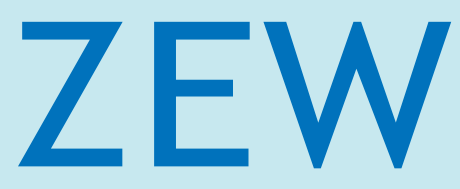

Zentrum für Europäische Wirtschaftsforschung $\mathrm{GmbH}$

Centre for European

Economic Research 
Discussion Paper No. 09-077

\title{
Social Preferences under Risk - An Experimental Analysis
}

\author{
Christiane Bradler
}

Download this ZEW Discussion Paper from our ftp server:

ftp://ftp.zew.de/pub/zew-docs/dp/dp09077.pdf

Die Discussion Papers dienen einer möglichst schnellen Verbreitung von neueren Forschungsarbeiten des ZEW. Die Beiträge liegen in alleiniger Verantwortung der Autoren und stellen nicht notwendigerweise die Meinung des ZEW dar.

Discussion Papers are intended to make results of ZEW research promptly available to other economists in order to encourage discussion and suggestions for revisions. The authors are solely responsible for the contents which do not necessarily represent the opinion of the ZEW. 


\section{Non-Technical Summary}

Traditional economic theory assumes individuals to be entirely rational actors who are solely maximizing their own utility. However, various experimental studies show that individuals do not necessarily conform to the behavioral assumption of Homo economicus. Many subjects do not solely focus on their own material gain but also care about fairness and equality. In contrast to previous research, this study addresses the persistence of these social preferences when risk comes into play.

In our daily lives, we have to take many decisions which have consequences for other people. At the same time, many of these come with potential risks to one's own and to other people's utility. For instance, a student who allows his classmate to copy in an exam has to weigh off his willingness to share his knowledge against the risk of being caught and punished. In the workplace, employees have to decide whether or not to behave in a fair manner towards their colleagues and share important information, even though this may reduce their chances of being promoted.

In order to investigate the interaction of social preferences and risk, the first part of the experiment elicits subjects' individual risk preferences. Here, subjects are faced with several choice problems each of which requires them to choose between a certain amount of money and a lottery where the latter offers to gain a small or a large amount of money by tossing a coin. In the second part of the experiment, subjects are randomly paired. The same choice problems are repeated but now the subject's decisions also have consequences for the (potential) amount of money which another, anonymous subject receives. Finally, the payoffs for both subjects are determined by one random decision.

The results indicate that many people are willing to bear more risk (or to forego a larger potential gain) when this increases the payoff of another, anonymous subject who would otherwise receive a very small payoff or nothing at all. The largest deviations from individual risk preferences are observed when the payoffs for both subjects can be perfectly equalized. By contrast, the subjects' choices also suggest that envy causes a crowding out of benevolent behavior when the other subject is able to receive a better payoff than the decision maker. The observations provide further evidence that a need for fairness and equality fundamentally influences individual decision-making processes. 


\section{Das Wichtigste in Kürze}

Die traditionelle ökonomische Theorie geht davon aus, dass Individuen vollständig rational handelnde Akteure sind, die ausschließlich ihren eigenen Nutzen maximieren. Zahlreiche experimentelle Studien zeigen jedoch, dass die Verhaltensannahme des Homo oeconomicus häufig zu kurz greift. Viele Experimentteilnehmer sind nicht ausschließlich auf ihren materiellen Eigennutz fokussiert, sondern haben auch eine starke Präferenz für Fairness und Gleichheit. Im Gegensatz zu bisherigen Untersuchungen, beschäftigt sich die vorliegende Studie mit der Frage, wie beständig diese sozialen Präferenzen sind, wenn Risiko ins Spiel kommt.

Im alltäglichen Leben treffen wir eine Vielzahl von Entscheidungen, die Konsequenzen für andere Menschen haben und gleichzeitig gewisse Risiken für unseren eigenen Nutzen wie auch den Nutzen anderer bergen. Stellt man sich beispielsweise einen Schüler vor, der seinem Mitschüler in einer Prüfung abschreiben lässt, so muss dieser seine Bereitschaft, Wissen zu teilen, gegen das Risiko abwägen, erwischt und mit einer schlechten Note bestraft zu werden. Am Arbeitsplatz müssen Arbeitnehmer abwägen, ob sie sich gegenüber ihren Kollegen fair verhalten und wichtige Informationen teilen, wenngleich sie dadurch eventuell ihre Chance auf eine Beförderung verringern.

Um die Wechselwirkung von sozialen Präferenzen und Risiko zu untersuchen, misst das Experiment zunächst die individuellen Risikopräferenzen. Hierfür wählen die Experimentteilnehmer in mehreren Entscheidungsproblemen jeweils zwischen einem sicheren Geldbetrag und einer Lotterie, wobei man in der Letzteren mit einem Münzwurf einen kleinen oder großen Geldbetrag gewinnen kann. Im zweiten Teil des Experiments werden die Teilnehmer zufällig in Gruppen von je zwei Personen eingeteilt. Die gleiche Aufgabe wird wiederholt, jedoch entscheidet nun jeder Experimentteilnehmer auch über den (möglichen) Geldbetrag, den ein anderer, anonymer Experimentteilnehmer bekommt. Eine am Ende zufällig ausgewählte Entscheidung bestimmt die Auszahlung beider Teilnehmer.

Die Ergebnisse zeigen, dass viele Menschen bereit sind, mehr Risiko für die eigene Auszahlung einzugehen (oder auf einen höheren möglichen Gewinn verzichten), wenn sie hierdurch die Auszahlung eines anderen, anonymen Teilnehmers erhöhen können, der ansonsten einen sehr kleinen Betrag oder gar nichts erhält. Die Bereitschaft von der eigenen Risikopräferenz abzuweichen ist dabei am größten, wenn die Auszahlungen beider Teilnehmer genau angeglichen werden können. Demgegenüber kann jedoch Neid wohlwollendes Verhalten verdrängen, wenn der andere Teilnehmer eine höhere Auszahlung als der Entscheidungsträger selbst bekommt. Die Beobachtungen liefern ein weiteres Indiz dafür, dass ein Bedürfnis nach Fairness und Gleichheit menschliches Entscheidungsverhalten grundlegend beeinflusst. 


\title{
Social Preferences under Risk - An experimental analysis
}

\author{
Christiane Bradler *
}

October 2009

\begin{abstract}
The literature on social preferences provides overwhelming evidence of departures from pure self-interest of individuals. Experiments show that people care about others' well-being and their relative standing. This paper investigates whether this type of behavior persists when risk comes into play. I devise an experiment which sheds light on the interrelation of risk and social preferences by measuring (1) individual risk preferences, (2) interpersonal risk preferences, and (3) social preferences under certainty. The results reveal that a large share of subjects choose to accept more risk or less potential gain than individually preferred in order to increase another subject's payoff. Further, the willingness to do so appears to be influenced by the "need" of the other person and her potential relative standing. Surprisingly, the results do not suggest that a subject's social behavior under risk is related to his social concerns exhibited under certainty.
\end{abstract}

JEL Classification: C91, D63, D81

Key words: social preferences, risk, other-regarding behavior, inequality aversion

I am grateful to the Max Planck Institute of Economics for support and granting access to the computer laboratory in Jena, Germany. In particular, I thank Christoph Vanberg, Werner Güth, Anthony Ziegelmeyer and Gary Charness for helpful suggestions and fruitful discussions. Please address all correspondence to bradler@zew.de. 


\section{Introduction}

During the last three decades, researchers have provided evidence that a remarkable share of individuals incorporate other-regarding concerns into their decision-making process. Field studies show how people care about fairness considerations in various economic settings (see, e.g., Kahneman et al., 1986; Blinder and Choi, 1990; et al., 1998). Laboratory experiments show that standard economic theory fails to predict individual decision making by assuming people to be solely self-interested and to exclusively maximize their own utility (see, e.g., Güth et al., 1982; Forsythe et al., 1994; Andreoni and Miller, 2002). Several approaches have been developed to explain a wave of various observations showing that people care about others' well-being. Andreoni $(1989,1990)$, for instance, provides a discussion of altruism and a "warm glow of giving" as the motivation behind benevolent behavior. Models by Bolton (1991) and Kirchsteiger (1994) focus on envy as an explanation for malevolent actions by agents. Approaches of inequality aversion (Fehr and Schmidt, 1999; Bolton and Ockenfels, 2000) combine the existence of altruism and envy, stating that people prefer equal payoffs and that actual behavior depends on their relative payoff position to others. Charness and Rabin (2002) present evidence from simple allocation games, showing that people are motivated rather to maximize social welfare, even if this implies a deviation from equality. They suggest a model which incorporates a maximin criterion, implying a preference to help the worst off combined with the willingness to maximize the aggregate surplus across all subjects.

Hence, evidence of social preferences seems undeniable. But so far, investigations on whether social behavior is consistent in situations involving risk are only at the beginning. Risk and uncertainty are omnipresent in our daily lives. Many decisions involving consequences for others also come with potential risks to one's own and the others' utility. This interaction of risk and social concerns can be applied to various fields of the economy such as tax schemes, social insurance, and distributive justice in general. But it does not only have important implications for economic settings. Applications can be extended even to decisions implying risks not only in a monetary dimension but also, in a broader sense, to utility in general. Thus, findings can shed light on human behavior, e.g., in negotiations and conflicts, medical decision making, consumer psychology as well as legal analysis and ethics. To the best of my knowledge, there are only a few experimental investigations which refer to an interaction of risk and social preferences. A related field is distributive justice, where some experimental investigations can be found (e.g., Frohlich et al. 1987, 1990; Beck, 1994; Herne and Suojanen, 2004; Swope et al., 2005). 
Beck (1994) measured individual risk preferences and preferences regarding the distribution of income separately, and his results suggest that preferences for more equal distributions can largely be explained by individual risk aversion. In contrast, Carlsson and Johansson-Stenman (2005) elicited individual risk preferences and inequality aversion separately by hypothetical choices among lotteries. They found that most people are willing to pay for a more equal society reflecting an individual inequality aversion. This raises the question whether people who face risky prospects for themselves and for others are solely motivated by self-interested monetary incentives (e.g. to insure against own income risks) or have a preference for equality per se.

The present study implicitly adopt this issue and explores whether people are willing to take more or less risk to achieve a more equal income distribution. The analysis focuses on individual risk preferences when subjects decide on their own payoff (individually), and when consequences for another person come into play (interpersonally).

Very little work has been done in this field. Charness and Jackson (2007) present results from a Stag Hunt Game, where one third of the subjects played a less risky strategy when their decision also affected another participant. Brennan et al. (2005) explore attitudes toward own and others' risks. They measured individuals' valuation of different prospects using a random price mechanism (Becker et al., 1964). The prospects included consequences for the decision maker and another randomly paired person. Valuations were elicited in the form of a willingness-to-pay to acquire the prospect and a willingness-to-accept to sell the prospect. In total, subjects had to submit reservation prices for four different prospects, which allocated either a certain or a risky payoff to the decision maker and to another participant. A comparison of the valuations across the different prospects inferred attitudes toward the decision maker's and toward the other person's risk. Brennan et al. (2005) confirm that other-regarding concerns play a significant role when payoffs are certain, but that valuations decrease considerably when own payoff is risky. Moreover, regression results revealed no significant effect of the other's risk on individual bidding behavior. Brennan et al. (2005) conclude that results do not support any relation between attitudes to (own) risk and other-regarding concerns.

A follow-up study by Güth et al. (2005) replicated the design and simultaneously investigated the interrelation of other-regarding concerns and attitudes toward risk and delay. By adopting only the willingness-to-accept treatment, they also found some evidence supporting the existence of other-regarding concerns when the own payoff was certain. But as soon as risk (or delay) to own payoff came into play, subjects disregarded the other and solely focused on their own condition. Güth et al. (2005) explain this behavior by a cognitive "crowding out." 
If participants have to evaluate options involving risk (and/or delay) to their own reward, they ignore the others' well-being, although they exhibit other-regarding concerns in certain (and/or undelayed) environments. A distinctive feature of these studies is that all prospects involved consequences for another person, thus making a clear separation of individual risk preferences and interpersonal preferences under risk seems to be difficult.

Another study closely related to my own experiment is by Bolton and Ockenfels (2008). Focusing on the effect of relative standing on risk taking, they found that social comparison affects the attractiveness of risk taking significantly. They measured individual risk preferences by a given binary choice problem between a risky option and a safe option. Additionally, Bolton and Ockenfels (2008) conducted identical binary choice problems, where both options entailed varying consequences for another person's payoff. Their experimental results suggest that decision makers tend to be more risk-averse when the own choice is of consequence also for another person. On the other hand, subjects appear to be less risk averse when the safe option implies an unfair outcome. And finally, an unequal outcome seems to be more acceptable when it is due to chance.

The present study investigates risk taking and social preferences going beyond the work cited above. With the help of a Multiple Price List (MPL) design, I presented subjects with several arrays of choice problems between a lottery and a certain amount. Each list allowed to elicit (a range for) a certainty equivalent. Choices were measured individually and interpersonally, meaning when subjects' decisions entailed consequences also for another (randomly paired) participant. In addition, a simple dictator game was conducted to elicit social preferences when risk was not involved.

In sum, the experiment measured (1) individual risk preferences, (2) interpersonal risk preferences and (3) social preferences under certainty. Two treatments were conducted, each involving different choice problems in part (2) of the experiment. In the "More Risk Treatment," subjects were able to increase another person's payoff by taking more risk. In contrast, the "Less Potential Gain Treatment" implied the same when subjects accepted less risk, thereby making a sacrifice in terms of potential gain. In both treatments, a comparison of the choices in part (1) and (2) reveal that many subjects deviated from their individual risk preferences in order to increase another person's payoff. This suggests that benevolent social preferences also exist in situations involving risk. The results of the different choice problems additionally show that social behavior under risk differs when the other person's payoff varies in its magnitude and the latter's relative position toward the decision maker. Most benevolent choices were observed when the other person could obtain a zero or equal payoff otherwise. In contrast, 
malevolent choices increased when the other person could obtain a better payoff than the decision maker himself, supporting the existence of envy. Hence, the results generally indicate that other-regarding concerns affect risk-taking behavior. A dependency on relative positions suggests a choice pattern which is mostly in line with inequality aversion.

In the following, section 2 provides a detailed description of the experimental design. Section 3 presents the experimental results, before I discuss the findings in relation to results from other studies in section 4 , concluding with a short summary and pointing out perspectives for future research.

\section{Experimental Design}

\subsection{Procedure Design}

The experiment consisted of three parts to measure (1) individual risk preferences, (2) interpersonal risk preferences, and (3) social preferences under certainty using a Multiple Price List (MPL) procedure. ${ }^{1}$ The treatments were conducted in separate sessions. The "More Risk Treatment" elicited individuals' certainty equivalents for a given lottery. In the interpersonal task, subjects increased their opponent's payoff, when they made a riskier choice. The "Less Potential Gain Treatment" was designed to elicit a lottery which a subject preferred to a certain amount of money. Here, subjects increased their opponent's payoff, when they made a safer choice, thereby renouncing a potentially larger gain. Additionally, the interpersonal task of both treatments was conducted each with six different choice problems to investigate subjects' sensitivity to specific payoff levels. Part (3) of the experiment was a simple dictator game and identical in both treatments.

\subsubsection{More Risk Treatment}

In part (1) of the experiment, each participant was presented an ordered array of eleven binary choices between a lottery $L$ assigning $\underline{L}$ or $\bar{L}$ (with 0.5 probability each) ${ }^{2}$ and a certain amount $X$, where $x_{r} \in\left[x_{1}, x_{2}, \ldots, x_{11}\right]$ and $\underline{L} \leq X \leq \bar{L}$. In order to determine the final outcome of

\footnotetext{
${ }^{1}$ The MPL procedure was probably first used by Miller, Meyer and Lanzetta in 1969 and later adopted in different variations by Schubert et al. (1999), Barr and Packard (2002) and Holt and Laury (2005). A discussion about the MPL design and tests for framing effects can be found, e.g., in Andersen et al. (2006).

${ }^{2}$ The assignment of equal probabilities was chosen to avoid possible probability weighting by subjects as suggested by Kahnemann and Tversky (1979).
} 
the lottery, a (virtual) coin was tossed at the end of the experiment, where "Heads" or "Tails" indicated a payoff of $\underline{L}$ or $\bar{L}$ respectively.

As Table 1 illustrates, subjects were asked to make a decision in each row on whether they preferred either option A, the "risky choice," or option B, the "safe choice." While the lottery is the same in each row, the certain amount increases as one moves down the table. When the incentive of the certain amount is high enough, a person should cross over to option $\mathrm{B}$. The switching point from option A to option B reveals an interval for the individual's certainty equivalent. Hence, this MPL design offers a plain method to measure subjects' risk attitudes.

In part (2) of the experiment this basic concept was extended with consequences for another person. Therefore, subjects were randomly paired and one member of each group was randomly assigned to dictate an option for both. Table 2 illustrates an example. A self-interested dictator, ${ }^{3}$ who does not care about others, sticks to his individual preferences and should make the same choice as in part 1 in each row. However, if a dictator cares about the well-being of his opponent, he should deviate from his individual risk preferences. By switching to the safe option further down the list than individually preferred, a decision maker exhibits benevolent behavior (e.g. based on altruism). In contrast, a dictator who switches already further up the list than he did in the individual dimension, reveals malevolent other-regarding behavior (e.g. based on spitefulness or envy).

To control if other-regarding concerns of dictators might be sensitive to specific payoff levels, the interpersonal task was conducted with six different payoff combinations. This allowed to examine the consistency of other-regarding behavior when the recipient's payoff varied in its magnitude and also in its relative position toward the dictator. While the dictator's payoff option stayed the same in each choice problem, the payoff levels for the recipient varied as displayed in Table 3. The safe choice resulted in a zero or a very low payoff ${ }^{4}$ for the recipient. In the case where the dictator made the risky choice, the recipient's position was always improved in the sense of a higher payoff level, but additionally corresponded to a specific relative position to the dictator's payoff level. The recipient was either (1) still worse off than the dictator, (2) equal off, or (3) even better off than the dictator. ${ }^{5}$ Thus, in total, participants faced six different MPL's in a random sequence. For individuals with pure self-interest, it should not influence their choice whether the other person receives a zero or low payoff.

\footnotetext{
${ }^{3}$ Since the decision maker "dictates" an option for both players, I hereafter refer to him as the "dictator" and to his opponent as "recipient."

${ }^{4}$ The low amount accounted for $700 \mathrm{ECU}$, corresponding to $€ 2.15$.

${ }^{5}$ In order to avoid that decision makers are influenced by different risk levels (in the sense of standard deviation), options A and B each included the same standard deviation for both participants.
} 
Neither a persons' relative position to his counterpart play a role. A self-interested dictator $i$ should always submit his individual risk preference $S P_{i}^{i n d}$, independent of the available payoff levels offered to the recipient. Therefore, one can formulate the "self-interest hypothesis" that $\left(S P_{i}^{i n t}\right)$, the switching points of a subject $i$ in each choice problem of the interpersonal task, equal $\left(S P_{i}^{i n d}\right)$, the switching point in the individual task:

$$
H_{0}: S P_{i}^{\text {ind }}=S P_{i}^{\text {int }}
$$

where $i \in\{1,2, \ldots, N\}$ and int $\in\{M W 0, M E 0, M B 0, M W 1, M E 1, M B 1\}$ against the general alternative

$$
H_{1}: S P_{i}^{i n d} \neq S P_{i}^{i n t}
$$

\subsubsection{Less Potential Gain Treatment}

The Less Potential Gain Treatment uses a similar design. Subjects faced an ordered array of eleven binary choices in one list. ${ }^{6}$ As illustrated in Table 4, option A offers a fixed amount $X_{f}$ ("safe choice") and option B a lottery $L_{r}$ ("risky choice") with varying outcomes $\underline{L}_{r}$ and $\bar{L}_{r}$, each with 0.5 probability. The lottery outcome depends on the row $r$ in a sense that: $\underline{L}_{r}=1000+$ $((r-1) \cdot 100)$ and $\bar{L}_{r}=2000+((r-1) \cdot 100)$ with $1 \leq r \leq 11$. That means the lottery outcomes become more attractive from row to row in comparison to the fixed amount of option A. In case the certain amount is chosen the subject takes no risk but also sacrifices a larger potential gain offered by the lottery. In case the subject chooses the lottery, a (virtual) coin tossed by the computer at the end of the experiment determines the final outcome. Analogous to the More Risk Treatment, the observed switching point reveals information about a person's individual risk preferences. Table 5 shows how this basic design is extended in the interpersonal task. In this treatment, people who care about another person's payoff have the opposite incentives to deviate from their individual risk preferences. A subject exhibits positive other-regarding behavior by switching to the riskier choice later than in the individual task. By switching to the riskier option earlier, a person shows malevolent behavior. As displayed in Table 6, this treatment was also conducted with six different payoff combinations for the recipient by keeping the dictator's payoff options constant.

\footnotetext{
${ }^{6}$ In the following, I will refer to one list as one choice problem since only the switching point had to be submitted.
} 
As in the More Risk Treatment, the following "self-interest hypothesis" can be formulated:

$$
H_{0}: S P_{i}^{i n d}=S P_{i}^{i n t}
$$

where $i \in\{1,2, \ldots, N\}$ and $i n t \in\{L W 0, L E 0, L B 0, L W 1, L E 1, L B 1\}$ against the general alternative

$$
H_{1}: S P_{i}^{i n d} \neq S P_{i}^{i n t}
$$

Finally, both treatments included an identical part 3: a simple dictator game. Subjects were asked how they would like to divide a fixed amount of money between themselves and the other subject ${ }^{7}$. People's giving behavior provides a useful benchmark for their other-regarding preferences in a certain environment. A comparison to other-regarding preferences under risk may indicate if (and to what extent) they are related to each other.

\subsection{Implementation}

The experiment was conducted at the experimental computer laboratory of the Max Planck Institute on the campus of the University of Jena (Germany). Both treatments were programmed using the software z-Tree (Fischbacher, 2007) and participants were recruited by way of the Online Recruitment System ORSEE (Greiner, 2004). When the participants entered the laboratory, they were randomly assigned to isolated terminals. All subjects were provided with the same written instructions, and they were informed that their payment at the end of the session would consist of a $2.50 €$ show-up fee plus the payoff from the experiment. The unit of experimental money was ECU (Experimental Currency Unit), where $325 \mathrm{ECU}=1 €$. Average earnings amounted to approx. $6 €$, excluding the show-up fee.

I conducted two separate sessions with a total of 58 subjects, 26 of them participating in the Less Potential Gain Treatment and 32 in the More Risk Treatment. At the beginning of each session, subjects were randomly paired with another subject whose identity was not revealed at any time. Both experiments consisted of three parts which were conducted separately one after the other. For each part, subjects first received detailed instructions. Then control questions were asked to check if they had understood the rules correctly, after which the experiment was conducted.

Parts 1 and 2 presented nine MPLs in total. Part 1 included the relevant list for the individual

\footnotetext{
${ }^{7}$ The amount to be distributed accounted for $4000 \mathrm{ECU}$, corresponding to $€ 12.40$.
} 
task and two additional MPLs, which were not relevant but were used to distract subjects from the experimenter's intentions. The six lists in part 2 were presented in a varying order such that both columns for the other subject differed from the previous one.

When facing a MPL, subjects were told to select only their switching point, by clicking either their last preferred row for option A or their first preferred row for option B; all other rows were marked automatically. ${ }^{8}$ In order to minimize portfolio selection among the potential payoffs of all choice problems and tasks, a random draw at the end of the experiment decided for each pair of subjects which single decision from all three parts would determine the final payoffs. After all parts were completed and final payoffs announced, subjects were asked to answer a short questionnaire concerning a few socioeconomic characteristics such as age, gender, academic discipline as well as their monthly disposable income.

\section{Experimental Results}

\subsection{More Risk Treatment}

Since the treatments measure risk preferences in two different variations, they are not directly comparable and hence presented separately.

Thirty-two students participated in the session of the More Risk Treatment, $43.75 \%$ of whom were male and $56.25 \%$ female. They came from a variety of disciplines, but as many as $25 \%$ came from economic disciplines. Their average age was approx. 23, and they stated an average disposable income of $508.00 €$. Please note that in the following I will refer to switching points as SPs, which subjects submitted in parts (1) and (2) of the experiment. The SP indicates the row in which the subject chose option A (the lottery) last before switching to option B (the certain amount).

\subsubsection{PART 1 - Individual Risk Preferences}

The individual SPs largely indicate a risk-neutral choice: about $66 \%$ of the subjects switched to the certain amount in row 6 or 7 . Approximately $28 \%$ can be described as risk averse because

\footnotetext{
${ }^{8}$ This offered subjects a convenient way to enter their decisions and, at the same time, avoided violations of transitivity. Since the MPL procedure provides an ordered array of choices, I did not expect many violations of transitivity. Furthermore, previous experiments using this procedure report only little evidence on multiple switching points (see, e.g., Holt and Laury (2002)). But of course, behavioral biases due to this specific MPL procedure cannot be excluded.
} 
they revealed a smaller certainty equivalent, and only about $6 \%$ exhibited risk-seeking behavior by switching further down the list. An individual switching point of 5 was the average and also most frequent choice. ${ }^{9}$

\subsubsection{PART 2 - Interpersonal Risk Preferences}

In part (2), the interpersonal choice problems still show row 5 as the most frequent choice. However, many subjects changed their choice when consequences for another person came into play. Figure 1 in the Appendix displays histograms on all observed SPs. In order to shed light on the potential impact of specific payoff levels, it is useful to calculate the differences between interpersonal and individual SPs to directly gain information about the magnitude of deviations. The mean difference ranges between 0 in the choice problem MB1 and 1.53 (rows) in the choice problems MW0 and ME0. Depending on the offered payoff levels, between 25 and $41 \%$ chose to stick to their individual preferences. All others deviated either in a negative way (revealing a smaller certainty equivalent and decreased the recipient's payoff) or in a positive manner (revealing a larger certainty equivalent and increasing the recipient's payoff). If one considers all differences (across all subjects and choice problems), then $33 \%$ are zero, $24 \%$ are negative, and the biggest share of $43 \%$ is positive. ${ }^{10}$

Boxplots in Figure 2 show that, altough the median in each choice problem is zero, the dispersion of the differences clearly demonstrates strong positive deviations and many positive extreme values. Solely the choice problems MB0 and MB1 (including a better payoff for the recipient) are distributed more evenly around the median.

\subsubsection{PART 3 - Dictator Game}

In addition to parts (1) and (2), I conducted a simple dictator game to elicit subjects other-regarding preferences under certainty. The results indicate a large share of benevolent behavior in the subject pool. The transferred amount to the recipient generally ranged between 0 and $50 \% .{ }^{11}$ The average transferred amount was 1040.63 ECU of the available 4000 ECU

\footnotetext{
${ }^{9}$ The individual SPs show significant correlation with some socioeconomic characteristics. Positively correlated (Spearman rank correlation) are age $(\mathrm{p}<0.1)$ and gender $(\mathrm{p}<0.05)$. For more details, see Table 7 in the Appendix.

${ }^{10}$ Detailed descriptive statistics on the differences between interpersonal and individual task(s) are presented in Table 8 in the Appendix. Average differences per subject (across treatments) do not show significant correlation with socioeconomic characteristics. For the exact Spearman rank correlations, see Table 7 in the Appendix.

${ }^{11}$ Surprisingly, two subjects submitted $75 \%$, which raises the question of whether the task was possibly misunderstood by them.
} 
(std. dev.: 1038.16 ECU), which corresponds to approx. $26 \%$ of the pie. In total, $37.50 \%$ of the participants gave nothing, $19 \%$ gave up to $25 \%$ of the pie, and a large share of $43.75 \%$ of the subjects transferred more than $25 \% .^{12}$

\subsubsection{Joint Analysis}

In the following, I focus on comparisons between SPs from the individual task and interpersonal tasks. In section 2, I formulated a self-interest hypothesis, stated in (1), that a solely self-interested subject would choose the same SP in all choice problems independent of potential payoffs for another person. In order to test this hypothesis, I conducted Wilcoxon signed rank tests on individual SPs vs. interpersonal SPs to utilize information on the direction as well as the relative magnitude of the differences within pairwise comparisons. As displayed in Table 9, each choice problem of part 2 was compared separately to the individual task. In total, the SPs in four of the six choice problems in the interpersonal task are significantly different from the individual task. Hence, the self-interest hypothesis can be rejected in four of six interpersonal choice problems. Table 9 shows that the SPs differ significantly when payoffs for the recipient in the risky option are still worse or equal. In contrast, a better payoff for the recipient in the risky option let more subjects choose the same or even a lower SP than they have done individually. This indicates that the relative payoff levels offered to the recipient seemed to play a role in subject's other-regarding preferences. Furthermore, choice problems offering a zero payoff for the recipient show lower $\mathrm{p}$-values than those which entailed a small minimum payoff to the recipient. This suggests to take a closer look at potential effects evoked by the different monetary consequences for the recipient.

In the following, I will present the results from the estimation of random effects models, which offer the possibility to compare all interpersonal tasks at once to the individual task and additionally make use of individual-level data. Due to the within-subject design of the experiment, observations are not independent of each other. Therefore, random effect models allow switching points to be analyzed by taking correlations within the multiple observations per subject into account. ${ }^{13}$ Table 10 provides the results from regressing all observed SP's (individual and interpersonal) on dummy variables for each interpersonal choice problem. In

\footnotetext{
${ }^{12}$ Correlations between the dictator game and socioeconomic characteristics show a significant negative correlation of income $(\mathrm{p}<0.05)$. Results of all correlations can be found in Table 7 in the Appendix.

${ }^{13}$ For all presented random effects models a Hausman test (Hausman, 1978) confirmed that random effects are consistent and efficient $(\mathrm{p}>0,50)$. In addition, for all presented regression models I tested all possible interactions between SP's in interpersonal tasks and socioeconomic characteristics none of them showing significance.
} 
the model, the individual task serves as baseline, and coefficients for the interpersonal choice problems reveal how switching points differed from this baseline treatment. The first two columns show the coefficients from a linear random effects model estimated by a maximum likelihood estimator. ${ }^{14}$ The first column includes socioeconomic characteristics as explanatory variables for switching points in all treatments. Age and gender do not show significant influence on people's SP, whereas a larger disposable income has a small positive effect on SPs. An even larger but negative effect is exhibited by the field of study. According to the results, economics students switched to the safe option about two rows earlier than students from other disciplines. ${ }^{15}$ The second column shows the reduced model, omitting socioeconomic characteristics and solely presenting treatment dummies. Apart from treatment MB1, which included the small minimum payoff in the safe option and a better payoff for the other person in the risky option, all other treatments are significantly different from the individual task. Highly significant, positive coefficients show that subjects deviated from their individually preferred row on average by 1.06 to 1.53 rows. This indicates that an undeniable share of subjects accepted more risk and chose to increase the other subject's payoff. By comparing the magnitude of the treatment coefficients, one can recognize that especially treatments including a zero payoff in the safe choice have larger coefficients. These results are also confirmed by two other random effects models, namely a random effects tobit model (column 3) and an ordered probit model (column 4).

A tobit model has the appealing feature of (relatively) overweighting observations at the lower and upper limit of a censored dependent variable. This is useful to apply here because the MLP design limits subjects' SPs to the given range of 0 to 11 . Since some subjects even chose the lottery eleven times, one could imagine that they might still have preferred the risky option, if option B had offered even higher amounts than the maximum outcome of the lottery. Estimated coefficients of the tobit model are slightly larger but generally indicate the same results as the linear random effects model.

The ordered probit model ${ }^{16}$ shown in column 4 also serves as an appropriate framework to analyze SPs since responses to the MLPs conform to ordinal and ordered data. In contrast to linear models, it has the distinctive feature that differences in responses between treatments are

\footnotetext{
${ }^{14}$ Residuals are normally distributed (Kolmogorov-Smirnov-Test, $\mathrm{p}>0.5$ for the model in column 1 and $\mathrm{p}>0.2$ for the model in column 2.)

${ }^{15}$ Since the dependent variable contains all SPs (individual and interpersonal), coefficients do not reveal information of whether economic students were individually more risk averse than other students or deviated less in the interpersonal treatments.

${ }^{16}$ A review of the ordered probit model is provided by Daykin and Moffatt (2002).
} 
not expected to be the same. ${ }^{17}$ The question of whether responses can be interpreted as linear or only strictly ordinal is surely arguable and related to further assumptions on individual utility functions as well as the underlying theory on choice under risk. The design of this experimental study required some basic assumptions; however, the elicitation of certainty equivalents pursued measuring risk preferences without specific assumptions on the underlying theory of choice under risk. For this reason, I present different regression models to demonstrate the consistency of the results independent of the approach used to interpret the data.

The results of the probit model show consistency with the coefficients of other models, and the latter fits the data best in regard to the Akaike Information Criterion ${ }^{18}$ which is shown at the bottom of Table 10. People's propensity to take more risk was significant in all treatments except MB1, where the coefficient was even negative. As already suggested by the Wilcoxon signed rank tests, people deviated most strongly in the choice problems ME0 and MW0.

The findings generally support concepts like inequality aversion or aggregate surplus maximization. In both treatments, an increase in equality generally also implied an increase in the aggregate surplus. It was not the main intention to observe a motivation to equalize or to maximize social welfare separately. In choice problems where an increase in the recipient's payoff entailed a still worse or an equal relative position, both concepts (inequality aversion and aggregate surplus maximization) could explain the observed behavior. However, it speaks in favor of inequality aversion rather than social welfare maximization, that benevolent behavior decreased when the choice problem offered a small minimum or better payoff to the recipient, suggesting that positive social preferences were "crowded out." This supports that envy outbalances the willingness to help when the "need" of the other agent is less strong. Inequality aversion can explain this behavior if one assumes that, the decision maker's disutility is larger when the other is better off than his disutility when he is better off himself. Contrarily, someone who maximizes social welfare would, in any choice problem, choose option A because it always included a larger aggregate payoff than option B.

Based on the finding of other-regarding preferences under risk, the within-subject design of the experiment allows another interesting investigation. Since a large fraction of the subject pool

\footnotetext{
${ }^{17}$ For example, assume someone who exhibited $S P^{i n d}=4$ and $S P^{M E 0}=7$ and someone who submitted $S P^{i n d}=6$ and $S P^{M E 0}=9$, then a linear model assumes this difference to be the same. In an ordered probit model, this assumption is not implicit because all possible values of the dependent variable are taken as categories, only reflecting ordinality.

${ }^{18}$ The Akaike's Information Criterion rewards the goodness of fit but also includes a penalty that increases with the number of estimated parameters, discouraging overfitting. Thus, it attempts to find the model that best explains the data with a minimum of free parameters. It is given by $A I C=2 k-2 \ln (L)$, where $k$ is the number of parameters in the statistical model and $L$ the maximized value of the likelihood function for the estimated model The preferred model is the one with the lowest AIC value.
} 
also showed benevolent behavior in the simple dictator game in part (3), the assumption seems obvious that other-regarding preferences under certainty and under risk are somehow related to each other. Surprisingly, correlation coefficients of the transferred amount in the simple dictator game with the differences between interpersonal and individual risk task did not show any substantial relation. I also checked for correlations of the latter with dummy variables for subjects transferring an amount of zero or an amount larger than $25 \%$ of the pie. Only for the choice problem ME0, a weak positive correlation could be found with the transferred amount in the dictator game, and for MB0 with dictators who gave more than 25\% (Spearman rank correlation, $\mathrm{p}<0.1)$. However, this finding can be due to the relatively small sample size and should be checked for robustness in further investigations.

\subsection{Less Potential Gain Treatment}

Twenty-six students participated in this treatment, $42.31 \%$ of whom were male and $57.69 \%$ female. Similar to the other session, they came from a variety of disciplines with a share of $20 \%$ from economic disciplines. The average age was approx. 24, and subjects stated an average disposable income of approx. $456.00 €$. Please note that in this treatment the SPs indicate the row in which the subject chose the safe option A (the certain amount) last before switching to the risky option B (the lottery).

\subsubsection{PART 1 - Individual Risk Preferences}

The individual choices largely indicate risk-averse and risk-neutral preferences. About 50\% of the subjects chose a SP of 7 or larger which means they only preferred lotteries with an expected value greater than the offered fixed amount of option A. Another $42.30 \%$ of the subjects submitted a SP of 5 or 6 , which can be interpreted as a risk-neutral choice. Only $7.70 \%$ of the subjects preferred the lottery already further up the list, when its expected value was smaller than the offered fixed amount. These participants revealed a risk-seeking behavior. The observed SPs show that the rows 6 and 7 were the most frequent choices. ${ }^{19}$

\footnotetext{
${ }^{19}$ The individual SPs in the Less Potential Gain Treatment showed no significant correlation with socioeconomic characteristics. For more details on Spearman rank correlation coefficients, see Table 11 in the Appendix.
} 


\subsubsection{PART 2 - Interpersonal Risk Preferences}

The different interpersonal tasks reveal considerable variations in the frequency of safe choices. In general, the average SP in all interpersonal choice problems outstrip the average SP of the individual task. Histograms in Figure 3 of the Appendix reveal that, especially in choice problems offering a potential zero payoff for the recipient in the risky option, an undeniable share of subjects even chose a SP of 11 . Thus, they never preferred the risky option.

Differences between interpersonal and individual SP(s) provide us with more information on the magnitude of deviations. The mean difference ranges between 0.42 (rows) in the choice problem LB1 and 1.53 (rows) in LE0. Depending on the choice problem, between 31 and $46 \%$ chose to stick to their individual preferences. Accordingly, the remaining share deviated in a negative way (prefering more potential gain and decreasing the recipient's payoff) or in a positive manner (forgoing more potential gain and increasing the recipient's payoff). Considering all differences (across all subjects and choice problems), $40.4 \%$ are zero, $17.3 \%$ are negative, and the biggest share of $42.3 \%$ are positive. ${ }^{20}$

In Figure 4, boxplots show that the differences between interpersonal and individual task(s) are concentrated above zero. Thus, most subjects preferred the certain amount in more rows than in the individual task. Although SPs in four of six choice problems again show a median of zero, the dispersion mainly ranges over positive values. It is especially striking that the choice problems, including a zero payoff for the other person in the risky option (LW0, LE0 and LB0), show a larger dispersion than the others. For the Less Potential Gain Treatment this also suggests an influence of specific payoff levels on people's choice behavior. ${ }^{21}$

\subsubsection{PART 3 - Dictator Game}

As part (3) of the treatment, I conducted a simple dictator game. The subject pool also indicated a large share of subjects with positive other-regarding preferences under certainty. The transferred amount to a recipient ranged for the most part between 0 and 50\%, with an average of $24.54 \% .{ }^{22}$ In total, $30.80 \%$ gave nothing, $33 \%$ gave up to $25 \%$ of the pie, and again

\footnotetext{
${ }^{20}$ Detailed descriptive statistics of differences between interpersonal and individual SPs per treatment are provided in Table 12 in the Appendix.

${ }^{21}$ Mean differences per subject (across treatments) do not show significant correlation with socioeconomic characteristics. For more details on the exact Spearman rank correlation coefficients and significance levels, see Table 11 in the Appendix.

${ }^{22}$ This corresponds to approx. 982 ECU of the available $4000 \mathrm{ECU}$, with a standard deviation of 863.53 ECU. Similar to the More Risk Treatment, where two subjects transferred even more than 50\%, here one subject
} 
the largest share of the subjects transferred more than $25 \%$, namely $46.20 \% .^{23}$

\subsubsection{Joint Analysis}

Similar to the More Risk Treatment, observed preferences are merged into a joint analysis to conduct comparisons and analyze their relation in more detail. Again, I conducted Wilcoxon signed rank tests on individual SPs vs. interpersonal SPs to test the hypothesis that SPs are equal across all choice problems independent of the consequences for the recipient's payoff. Each choice problem of part 2 was compared pairwise to the individual task. In total, SPs in four of six choice problems are significantly different from the individual task and the self-interest hypothesis can be significantly rejected. Table 13 illustrates that both choice problems offering an equal payoff as well as those offering a worse or better payoff, but a zero payoff otherwise, show significance. In contrast, preferences in the choice problems LW1 and LB1 do not differ significantly from individual risk preferences. This indicates that both, the potential zero payoff as well as the relative payoff levels offered to the recipient, seem to play a role in the subject's other-regarding preferences. The results further suggest that the possibility to equalize payoffs enhances positive other-regarding behavior. However, when a worse or better payoff is offered, it seems that the potential zero payoff has an influence on the motivation to choose the safe option more often.

Analogous to the More Risk Experiment, it is useful to extend this analysis by random effects models. The first two columns of Table 14 present the coefficients from the linear random effects model, where the first includes the socioeconomic characteristics: gender, age, field of study as well as monthly disposable income. None of these characteristics showed a significant influence on subjects SPs. As suggested by the Wilcoxon signed rank test, the choice problems LE0 and LB0 show significant positive coefficients. The choice problem LE0 indicates the largest influence on subjects' SPs. But the observed SPs in LB0 also exhibit remarkable deviations. Significant but rather low coefficients are presented for the choice problem LW1. This indicates a difference to previous results from the Wilcoxon signed rank test, where LW0 and LE1 instead of LW1 showed significance. This is probably caused by the fact that the random effects regressions compare treatments on the individual level, while the Wilcoxon test

submitted $83.75 \%$. Unfortunately, one cannot clearly conclude whether this decision happened by default or was taken on purpose.

${ }^{23}$ Correlations between the dictator game and socioeconomic characteristics show no significant correlation apart from gender. The coefficient for gender indicates a negative correlation between male students and generousity in the dictator game $(\mathrm{p}<0.01)$. Detailed results of all correlations can be found in Table 11 in the Appendix. 
compares only the ordered rankings of observations across all subjects. However, treatment LW1 shows only weak significance $(\mathrm{p}<0.1)$, whereby LW0 and LE1 narrowly missed that significant level ( $\mathrm{p}=0.116$ for both treatments). Results from a tobit model show slightly larger coefficients but in general indicate the same outcome. This is also the case for the ordered probit random effects model, where additionally LW0 becomes weakly significant $(\mathrm{p}<0.1)$.

In sum, the "need" of the other agent (in choice problems including a potential zero payoff) motivated subjects to forgo a larger potential gain to increase the other subjects' payoff. In particular, the combination of a potential zero payoff and a large increase in payoff, as offered by the equal or better payoff position, enhanced the most benevolent behavior. For both treatments, one can conclude that a combination of motives like inequality aversion and the "need" of another person can explain benevolent (or malevolent) choices under risk in this experiment. Efficiency concerns, as suggested by concepts of aggregate surplus maximization, can only explain part of the observations and is not in line with an increase in malevolent choices in tasks where the other agent was able to obtain a better payoff than the decision maker.

Finally, I checked also for the Less Potential Gain Treatment if other-regarding preferences under risk are correlated with subjects' other-regarding concerns in the simple dictator game at the end of the experiment. Apart from a weak negative correlation (Spearman rank correlation, $\mathrm{p}<0.1$ ) of subjects' deviation in the choice problem LW0 with a dummy variable for dictators who gave nothing, I found a substantial relation neither with the transferred amount in the dictator game nor with dummy variables for subjects who gave nothing or those who transferred more than $25 \%$ of the pie. Hence, this treatment also has the surprising result that other-regarding concerns under risk (as elicited in part 2) and in the certain environment of the dictator game (part 3) do not show any significant relation.

\section{Discussion and Conclusion}

As described at the beginning of this study, experimental evidence shows that people care about others' well-being. A large fraction of subjects seem to incorporate fairness considerations into their decision-making process and intentionally increase or decrease others' payoff, even it is costly to them. The present study has examined to what extent social concerns might play a role in decision making under risk. I have presented two treatments, both measuring (1) individual risk preferences, (2) interpersonal risk preferences and (3) social preferences under certainty. In the More Risk Treatment, subjects increased (decreased) another person's payoff by taking 
more (less) risk than individually preferred. In the Less Potential Gain Treatment, subjects forwent (preferred) a larger potential gain to increase (decrease) another subject's payoff. In each treatment, subjects faced several choice tasks in terms of the relative monetary payoffs that would result if the decision maker chose the option preferred by the other agent. Decision makers always had the choice between an option, where the recipient received a (potential) zero or small minimum payoff, and an option, where the recipients' payoff was increased and (a) still worse, (b) equal to, or (c) even better than the decision makers' payoff.

Several choice problems showed that subjects made a riskier choice (or forwent a larger potential gain) if this increased the other's payoff. This was particularly the case if the other person might receive a zero payoff otherwise. In contrast, subjects deviated less strongly from their individual choice when the alternative was a small minimum payoff for the recipient. Hence, people's benevolent behavior seems to be influenced by another person's "need".

The different relative positions offered to the decision maker provided the possibility to observe if concepts like inequality aversion might also provide an explanation for other-regarding behavior under risk. And indeed, the relative position seems to influence subjects' choices. Subjects chose to increase the others payoff particularly if this implied a worse or equal payoff for the latter. In the choice problem between an equal payoff and a zero payoff otherwise, subjects reported the strongest benevolent deviations from their individual choice. In contrast, if the recipient could obtain a better payoff than themselves, subjects chose this option only if the alternative implied a zero payoff. This observation clearly supports the existence of envy and suggests that social preferences are "crowded out" in case the "need" of the other agent is less evident.

Benevolent behavior was generally less strong in the Less Potential Gain Treatment. This treatment had the distinctive feature that if the subject chose not to increase the recipients payoff, the latter received a lottery involving a potential zero or small minimum payoff. While in the More Risk Treatment option B always implied the zero or small payoff for sure, here, the final outcome in option B was finally determined by chance so that the "need" of the other person was less striking. A subject's feelings of responsibility might be reduced because nature determines whether the recipient will indeed receive a very small amount or even nothing, and this might weaken other-regarding concerns. This would be in line with results from Bolton and Ockenfels (2008), who observed that an unequal outcome seems more acceptable when it is the result of a chance move.

Apart from a comparison of individual and interpersonal risk preferences, I conducted a simple dictator game at the end of each session to additionally measure individuals' social preferences 
under certainty. With the help of a correlation analysis of people's generosity under risk and under certainty I made the intriguing observation that there was no substantial relation. An individual's propensity to improve the other's payoff in the interpersonal risk task showed no significant correlation with the observed social behavior in the simple dictator game. Although it was not the main focus of my investigation, it keeps puzzling in which way social concerns are involved in the human decision-making process.

However, what the present analysis has accomplished is to provide new insights into how social preferences of individuals affect decision-making under risk. To the best of my knowledge, none of the existing theoretical frameworks, neither models of decision making under risk nor models of social preferences, can explain the observed behavior. The observation that subjects deviate from individual risk preferences, if consequences for another person are involved, conform to results of Charness and Jackson (2007) as well as Bolton and Ockenfels (2008), although these experiments were based on different decision settings. In particular, my results of the More Risk Treatment are in line with the recent finding of Bolton and Ockenfels (2008) that people are less risk averse when the safe option implies an unfair outcome.

In contrast to the studies by Brennan et al. (2005) and Güth et al. (2005), who elicited valuations of prospects, involving both certain and risky payoffs for oneself and another participant by a BDM design, my results show that other-regarding concerns are not necessarily "crowded out" by own risk. Rather, the observed behavior suggests that subjects prefer fair outcomes, even if this is costly in the sense of more (or less) risk. At this point, it is worth mentioning that subjects' responses might also be sensitive to the applied elicitation method. The question whether the incentives of the BDM mechanism reveal truthful valuations or subjects tend to overbidding is still a matter of controversial debates. ${ }^{24}$ Therefore, further comparative investigations are necessary to conclusively assess the potential biases of this method. In order to investigate the interaction of social concerns and risk preferences, I have favored the MPL design because it is easy to understand for subjects and suitable to reveal truthful preferences in the context addressed here. However, the specific application of a Multiple Price List, as presented here, makes substantial assumptions about the theoretical framework of decision making under risk, which are a topic of ongoing disputes.

In any case, more investigations on the interaction of risk and social preferences are desirable. As I pointed out in the introduction, the interrelation of risk preferences with fairness considerations has important implications for many economic and noneconomic settings. It is a challenge to future research to extend these investigations. Moreover, different elicitation

\footnotetext{
${ }^{24}$ See, e.g., Harrison and Rutström (2008).
} 
methods need to be applied to test the robustness of previous findings. Existing theoretical theories could then be adapted in light of these new evidences, and research could make a further approach to merge theories of social preferences and theories on choice under risk together. 


\section{Appendix}

Table 1: More Risk Treatment: Individual Task Design

\begin{tabular}{|c|c|c|c|c|c|}
\hline & $\begin{array}{r}\text { Op } \\
\text { You ge }\end{array}$ & $\begin{array}{l}\text { A } \\
\text { case of }\end{array}$ & Your & loice & $\begin{array}{c}\text { Option B } \\
\text { You get in case of }\end{array}$ \\
\hline & "Heads" & "Tails" & & B & "Heads or Tails" \\
\hline 1 & 1500 & 2500 & & & 1500 \\
\hline 2 & 1500 & 2500 & & & 1600 \\
\hline 3 & 1500 & 2500 & & & 1700 \\
\hline 4 & 1500 & 2500 & & & 1800 \\
\hline 5 & 1500 & 2500 & & & 1900 \\
\hline 6 & 1500 & 2500 & & & 2000 \\
\hline 7 & 1500 & 2500 & & & 2100 \\
\hline 8 & 1500 & 2500 & & & 2200 \\
\hline 9 & 1500 & 2500 & & & 2300 \\
\hline 10 & 1500 & 2500 & & & 2400 \\
\hline 11 & 1500 & 2500 & & & 2500 \\
\hline
\end{tabular}

Table 2: More Risk Treatment: Interpersonal Task Design

\begin{tabular}{|c|c|c|c|c|c|c|c|c|}
\hline & \multicolumn{4}{|c|}{ Option A } & & & \multicolumn{2}{|c|}{ Option B } \\
\hline & \multicolumn{2}{|c|}{ You get in case of } & \multicolumn{2}{|c|}{ The other gets in case of } & \multicolumn{2}{|c|}{ Your choice } & You get in case of & The other gets in case of \\
\hline & "Heads" & "Tails" & "Heads" & "Tails" & $\mathbf{A}$ & B & "Heads" or "Tails" & "Heads" or "Tails" \\
\hline 1 & 1500 & 2500 & 1500 & 2500 & & & 1500 & 0 \\
\hline 2 & 1500 & 2500 & 1500 & 2500 & & & 1600 & 0 \\
\hline 3 & 1500 & 2500 & 1500 & 2500 & & & 1700 & 0 \\
\hline 4 & 1500 & 2500 & 1500 & 2500 & & & 1800 & 0 \\
\hline 5 & 1500 & 2500 & 1500 & 2500 & & & 1900 & 0 \\
\hline 6 & 1500 & 2500 & 1500 & 2500 & & & 2000 & 0 \\
\hline 7 & 1500 & 2500 & 1500 & 2500 & & & 2100 & 0 \\
\hline 8 & 1500 & 2500 & 1500 & 2500 & & & 2200 & 0 \\
\hline 9 & 1500 & 2500 & 1500 & 2500 & & & 2300 & 0 \\
\hline 10 & 1500 & 2500 & 1500 & 2500 & & & 2400 & 0 \\
\hline 11 & 1500 & 2500 & 1500 & 2500 & & & 2500 & 0 \\
\hline
\end{tabular}

Table 3: Interpersonal Choice Problems in the More Risk Treatment

\begin{tabular}{c|c|cc|cc}
$\begin{array}{c}\text { Relative } \\
\text { position }\end{array}$ & Choice & \multicolumn{2}{|c|}{ Risky choice } & \multicolumn{2}{c}{ Safe choice } \\
problem & Dictator & Recipient & Dictator & Recipient \\
\hline worse & MW0 & lottery $1500 / 2500$ & lottery $1000 / 2000$ & $1500 \leq x_{r} \leq 2500$ & 0 \\
& MW1 & lottery $1500 / 2500$ & lottery $1000 / 2000$ & $1500 \leq x_{r} \leq 2500$ & 700 \\
\hline equal & ME0 & lottery $1500 / 2500$ & lottery $1500 / 2500$ & $1500 \leq x_{r} \leq 2500$ & 0 \\
& ME1 & lottery $1500 / 2500$ & lottery $1500 / 2500$ & $1500 \leq x_{r} \leq 2500$ & 700 \\
\hline better & MB0 & lottery 1500/2500 & lottery 2000/3000 & $1500 \leq x_{r} \leq 2500$ & 0 \\
& MB1 & lottery 1500/2500 & lottery 2000/3000 & $1500 \leq x_{r} \leq 2500$ & 700 \\
\hline \hline
\end{tabular}


Table 4: Less Risk Treatment: Individual Task Design

\begin{tabular}{|c|c|c|c|c|}
\hline & $\begin{array}{c}\text { Option A } \\
\text { You get in case of }\end{array}$ & \multicolumn{1}{c|}{$\begin{array}{c}\text { Your Choice } \\
\text { You get in case of }\end{array}$} \\
\hline & "Heads" or "Tails" \\
\hline 1 & 2000 \\
\hline 2 & 2000 \\
\hline 3 & 2000 \\
\hline 4 & 2000 \\
\hline 5 & 2000 \\
\hline 6 & 2000 \\
\hline 7 & 2000 \\
\hline 8 & 2000 \\
\hline 9 & 2000 \\
\hline 10 & 2000 \\
\hline 11 & 2000 \\
\hline
\end{tabular}

Table 5: Less Risk Experiment: Interpersonal Task Design

\begin{tabular}{|c|c|c|c|c|c|c|c|c|}
\hline & \multicolumn{2}{|c|}{ Option A } & \multirow{2}{*}{\multicolumn{2}{|c|}{ Your choice }} & \multicolumn{4}{|c|}{ Option B } \\
\hline & \multirow{2}{*}{\begin{tabular}{|r|} 
You get in case of \\
"Heads" or "Tails" \\
\end{tabular}} & \multirow{2}{*}{$\begin{array}{c}\text { The other gets in case of } \\
\text { "Heads" or "Tails" } \\
\end{array}$} & & & \multicolumn{2}{|c|}{ You get in case of } & \multicolumn{2}{|c|}{ The other gets in case of } \\
\hline & & & $\mathbf{A}$ & $\mathbf{B}$ & "Heads" & "Tails" & "Heads" & "Tails" \\
\hline 1 & 2000 & 1500 & & & 1000 & 2000 & 0 & 1000 \\
\hline 2 & 2000 & 1500 & & & 1100 & 2100 & 0 & 1000 \\
\hline 3 & 2000 & 1500 & & & 1200 & 2200 & 0 & 1000 \\
\hline 4 & 2000 & 1500 & & & 1300 & 2300 & 0 & 1000 \\
\hline 5 & 2000 & 1500 & & & 1400 & 2400 & 0 & 1000 \\
\hline 6 & 2000 & 1500 & & & 1500 & 2500 & 0 & 1000 \\
\hline 7 & 2000 & 1500 & & & 1600 & 2600 & 0 & 1000 \\
\hline 8 & 2000 & 1500 & & & 1700 & 2700 & 0 & 1000 \\
\hline 9 & 2000 & 1500 & & & 1800 & 2800 & 0 & 1000 \\
\hline 10 & 2000 & 1500 & & & 1900 & 2900 & 0 & 1000 \\
\hline 11 & 2000 & 1500 & & & 2000 & 3000 & 0 & 1000 \\
\hline
\end{tabular}

Table 6: Interpersonal Choice Problems in the Less Risk Treatment

\begin{tabular}{|c|c|c|c|c|c|}
\hline \multirow{2}{*}{$\begin{array}{l}\text { Relative } \\
\text { position }\end{array}$} & \multirow{2}{*}{$\begin{array}{l}\text { Choice } \\
\text { problem }\end{array}$} & \multicolumn{2}{|c|}{ Safe choice } & \multicolumn{2}{|c|}{ Risky choice } \\
\hline & & Dictator & Recipient & Dictator & Recipient \\
\hline \multirow[t]{2}{*}{ worse } & LW0 & 2000 & 1500 & lottery $1000+z / 2000+z$ & lottery $0 / 1000$ \\
\hline & LW1 & 2000 & 1500 & lottery $1000+z / 2000+z$ & lottery $400 / 1400$ \\
\hline \multirow[t]{2}{*}{ equal } & LE0 & 2000 & 2000 & lottery $1000+z / 2000+z$ & lottery $0 / 1000$ \\
\hline & LE1 & 2000 & 2000 & lottery $1000+z / 2000+z$ & lottery $400 / 1400$ \\
\hline \multirow[t]{2}{*}{ better } & LB0 & 2000 & 2500 & lottery $1000+z / 2000+z$ & lottery $0 / 1000$ \\
\hline & LB1 & 2000 & 2500 & lottery $1000+z / 2000+z$ & lottery $400 / 1400$ \\
\hline
\end{tabular}

Note: $\mathrm{z}$ is increasing with row $\mathrm{r}$ in th following way: $\mathrm{z}=(\mathrm{r}-1)^{*} 100$ with $1 \leq \mathrm{r} \leq 11$. 

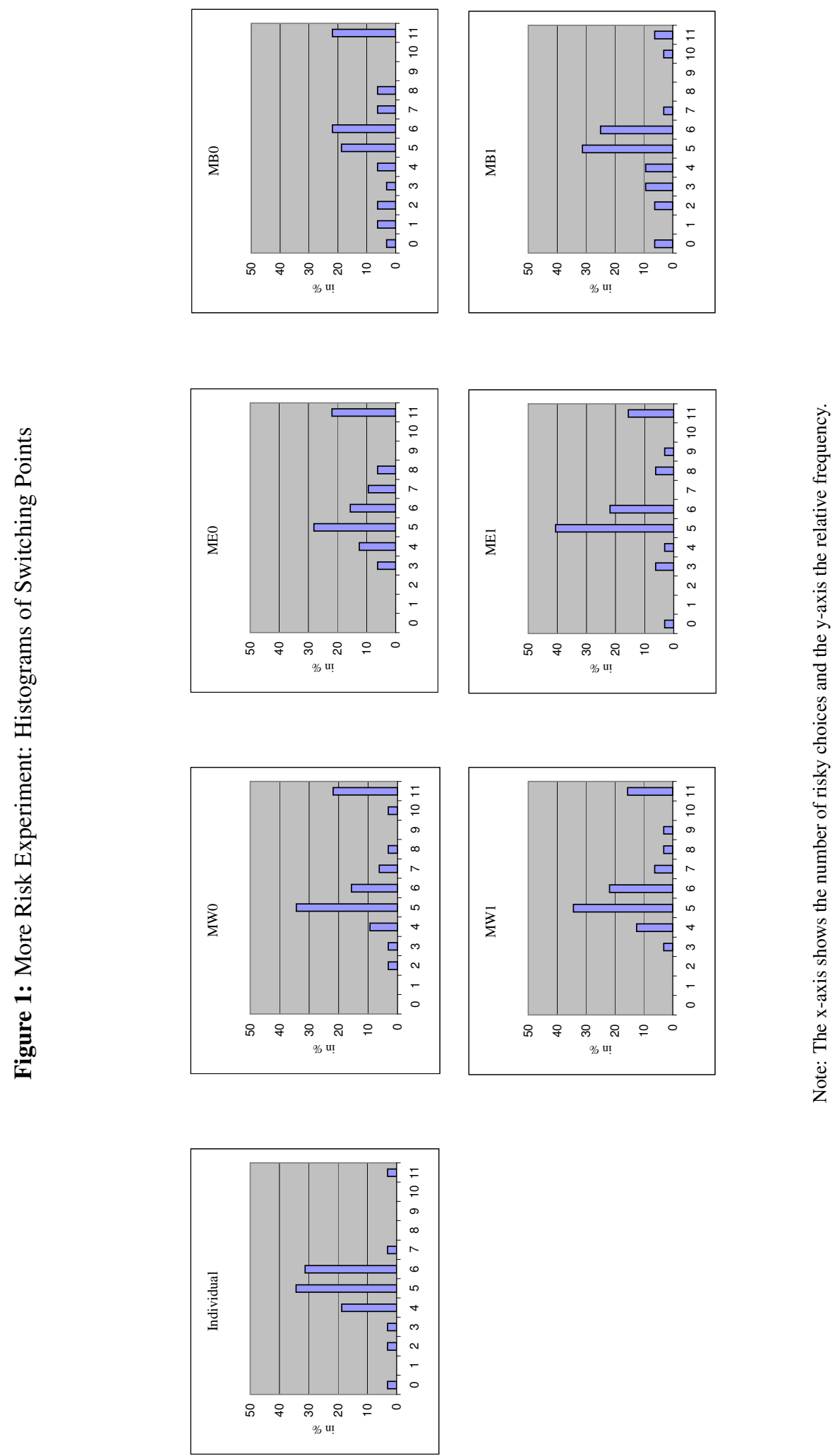
Table 7: More Risk Treatment: Spearman Rank Correlation Coefficients of Switching Points with Socio-Economic Characteristics

\begin{tabular}{ccccccc}
\hline \hline Characteristics & $\mathbf{S P}_{i}^{\text {ind }}$ & $\mathrm{p}$-value & Average SP $_{i}^{\text {int }}$ & $\mathrm{p}$-value & Dictator game & $\mathrm{p}$-value \\
\hline Age & 0.310 & $0.084^{*}$ & -0.230 & 0.205 & 0.119 & 0.518 \\
Gender & 0.423 & $0.016^{* *}$ & -0.250 & 0.969 & 0.095 & 0.605 \\
Income & 0.289 & 0.128 & -0.008 & 0.167 & -0.426 & $0.021^{* *}$ \\
Econ. Field of Study & -0.008 & 0.965 & -0.224 & 0.218 & 0.020 & 0.913 \\
\hline \hline
\end{tabular}

Note: Significance levels: $* * *=1 \%, * *=5 \%, *=10 \%$. Due to missing observations $\mathrm{N}=29$ for income correlations; for all others $\mathrm{N}=32$. Field of study refers to economic disciplines against all other disciplines.

Table 8: More Risk Treatment: Descriptive Statistics of Differences between Interpersonal and Individual Risk Preferences

\begin{tabular}{ccccccc}
\hline \hline & \multicolumn{9}{c}{ Choice Problems } \\
& \multicolumn{2}{c}{ worse } & \multicolumn{2}{c}{ equal } & \multicolumn{2}{c}{ better } \\
Min. & MW0 & MW1 & ME0 & ME1 & MB0 & MB1 \\
Mean & 1.53 & 1.25 & 1.53 & 1.09 & 1.06 & 0.00 \\
Max. & 11 & 8 & 8 & 11 & 11 & 7 \\
Std. Deviation & 2.93 & 2.46 & 2.58 & 2.84 & 3.33 & 2.64 \\
\hline \% of obs. $<\mathbf{0}$ & 21.9 & 15.6 & 18.8 & 21.9 & 28.1 & 37.5 \\
\% of obs. $=\mathbf{0}$ & 31.3 & 40.6 & 34.4 & 31.3 & 25.0 & 34.4 \\
\% of obs. $>\mathbf{0}$ & 46.9 & 43.8 & 46.9 & 46.9 & 46.9 & 28.1 \\
\hline \hline
\end{tabular}


Figure 2: More Risk Treatment: Boxplots of Differences between Interpersonal and Individual Risk Preferences

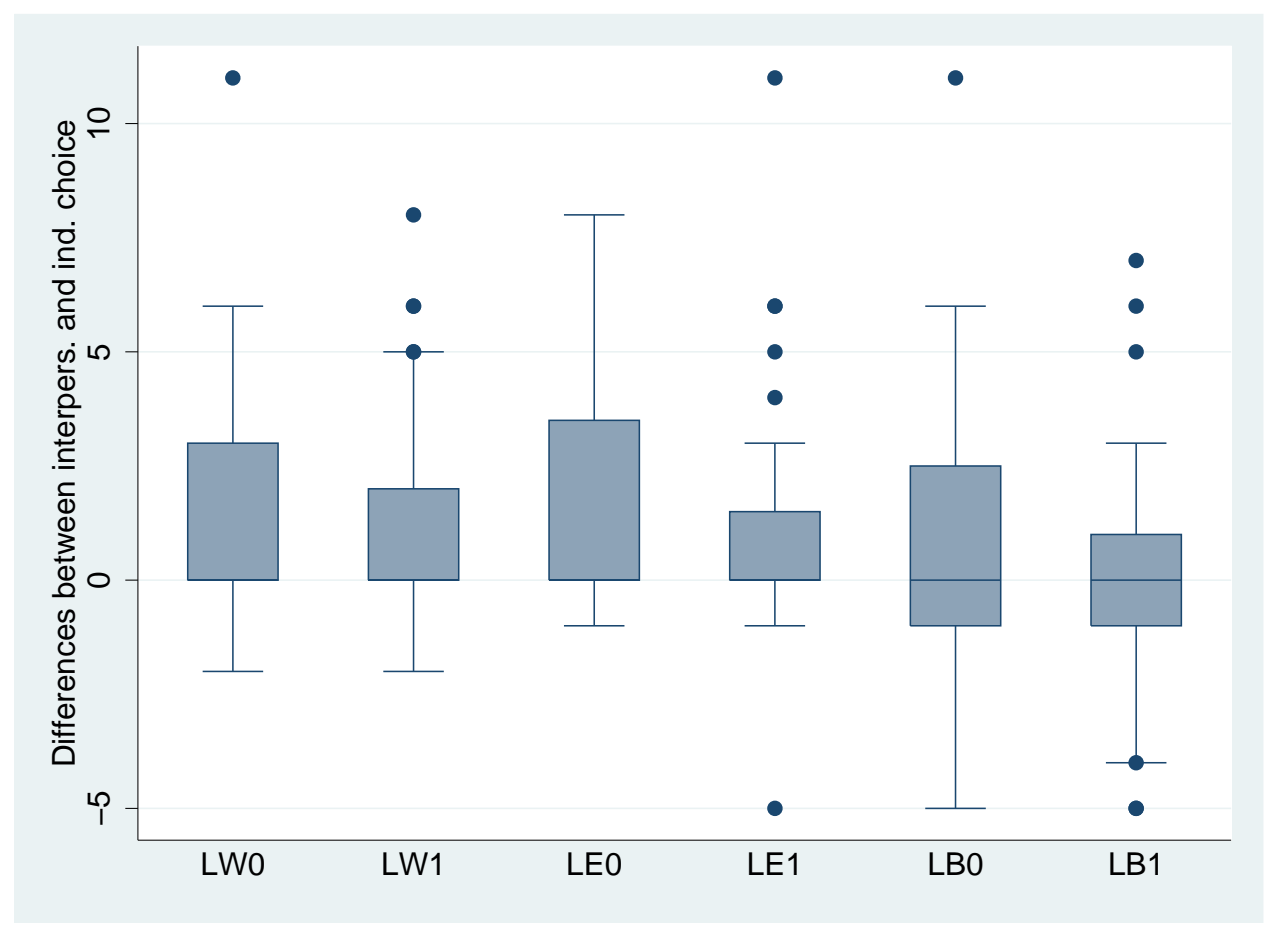

Table 9: More Risk Treatment: Two-sided Wilcoxon Signed Rank Test on Switching Points

\begin{tabular}{|c|c|c|c|}
\hline \multicolumn{4}{|c|}{ Comparisons between individual and interpersonal switching points } \\
\hline \multicolumn{2}{|c|}{ Choice problems } & Z Statistic & p-value \\
\hline individual & vs. MW0 & $-2.682^{a}$ & $0.007 * * *$ \\
\hline individual & vs. MW1 & $-2.556^{a}$ & $0.011 * *$ \\
\hline individual & vs. ME0 & $-2.905^{a}$ & $0.004 * * *$ \\
\hline individual & vs. ME1 & $-2.196^{a}$ & $0.028 * *$ \\
\hline individual & vs. MB0 & $-1.624^{a}$ & 0.104 \\
\hline individual & vs. MB1 & $-0.282^{b}$ & 0.778 \\
\hline
\end{tabular}

Note: Significance levels: $* * *=1 \%, * *=5 \%, *=10 \%, \mathrm{a}=$ positive ranks $>$ negative ranks, $\mathrm{b}=$ positive ranks $<$ negative ranks. 
Table 10: More Risk Treatment: Estimates of Random Effects Regression Models on Switching Points

\begin{tabular}{|c|c|c|c|c|}
\hline Choice problem & MLE1 & MLE2 & TOBIT & OPROBIT \\
\hline \multirow[t]{2}{*}{ MW0 } & $1.7241 * * *$ & $1.5313 * * *$ & $1.8127 * * *$ & $0.9279 * * *$ \\
\hline & $(0.3988)$ & $(0.3724)$ & $(0.4476)$ & $(0.2769)$ \\
\hline \multirow[t]{2}{*}{ MW1 } & $1.3448 * * *$ & $1.2500 * * *$ & $1.4503 * * *$ & $0.8189 * * *$ \\
\hline & $(0.3988)$ & $(0.3724)$ & $(0.4448)$ & $(0.2741)$ \\
\hline \multirow[t]{2}{*}{ ME0 } & $1.6897 * * *$ & $1.5313 * * *$ & $1.8143 * * *$ & $0.9782 * * *$ \\
\hline & $(0.3988)$ & $(0.3724)$ & $(0.4477)$ & $(0.2771)$ \\
\hline \multirow[t]{2}{*}{ ME1 } & $1.1379 * * *$ & $1.0938 * * *$ & $1.2553 * * *$ & $0.7126 * * *$ \\
\hline & $(0.3988)$ & $(0.3724)$ & $(0.4446)$ & $(0.2746)$ \\
\hline \multirow[t]{2}{*}{ MBO } & $1.2414 * * *$ & $1.0625 * * *$ & $1.2823 * * *$ & $0.6728 * *$ \\
\hline & $(0.3988)$ & $(0.3724)$ & $(0.4463)$ & $(0.2741)$ \\
\hline \multirow[t]{2}{*}{ MB1 } & 0.1034 & 0.0000 & -0.0100 & -0.0873 \\
\hline & $(0.3988)$ & $(0.3724)$ & $(0.4410)$ & $(0.2679)$ \\
\hline \multirow[t]{2}{*}{ Age } & 0.0816 & & & \\
\hline & $(0.1510)$ & & & \\
\hline \multirow[t]{2}{*}{ Income } & $0.0036 * *$ & & & \\
\hline & $(0.0018)$ & & & \\
\hline \multirow[t]{2}{*}{ Gender $($ male $=1)$} & -0.2317 & & & \\
\hline & $(0.7674)$ & & & \\
\hline \multirow[t]{2}{*}{ Econ. Field of Study } & $-2.1667 * *$ & & & \\
\hline & $(0.8582)$ & & & \\
\hline \multirow[t]{2}{*}{ Constant } & 1.9767 & $5.0625 * * *$ & $5.0875 * * *$ & \\
\hline & $(3.4905)$ & $(0.4494)$ & $(0.5315)$ & \\
\hline No. of observations & 203 & 224 & 224 & 224 \\
\hline AIC & 840.74 & 917.52 & 900.35 & 739.50 \\
\hline Log-likelihood & -407.3705 & -449.7584 & -441.1733 & -351.7513 \\
\hline
\end{tabular}

Note: Significance levels: $* * *=1 \%, * *=5 \%, *=10 \%$. The dependent variable is the switching point between option $\mathrm{A}$ and option B in all treatments, coded as the last row, where the subject chose the risky choice A. Column 1 and 2 are random effect models with maximum likelihood estimator (MLE). Column 3 is a random effect tobit model and column 4 is an ordered probit model (estimated using Gllamm in Stata). A lower no. of observations in the first column is due to missing values for income. Field of study refers to economic disciplines against all other disciplines. 

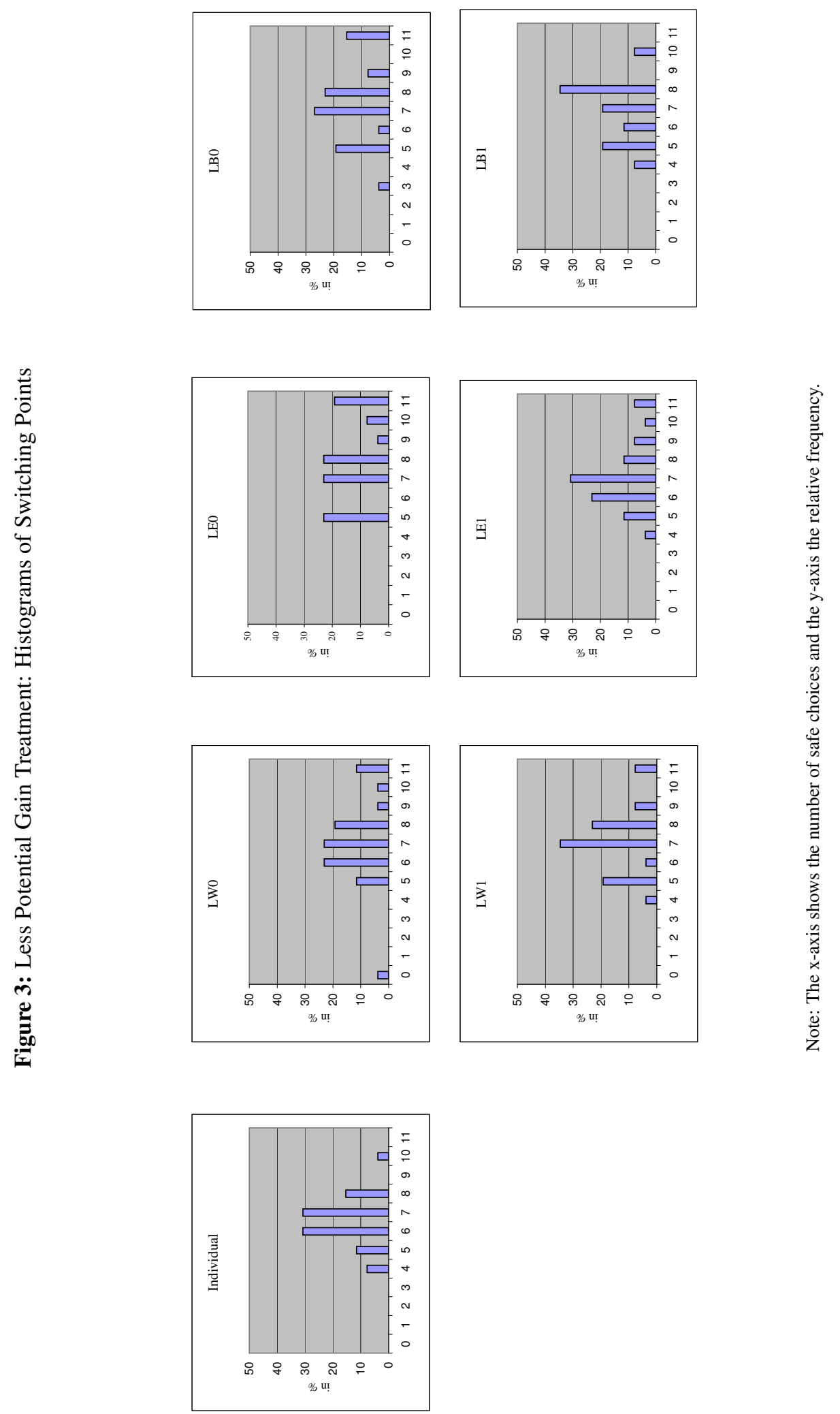
Table 11: Less Potential Gain Treatment: Spearman Rank Correlation Coefficients of Switching Points with Socio-Economic Characteristics

\begin{tabular}{ccccccc}
\hline \hline Characteristics & $\mathbf{S P}_{i}^{\text {ind }}$ & $\mathrm{p}$-value & Average $\mathbf{S P}_{i}^{\text {int }}$ & $\mathrm{p}$-value & Dictator game & $\mathrm{p}$-value \\
\hline Age & -0.154 & 0.463 & 0.066 & 0.752 & 0.076 & 0.718 \\
Gender & 0.118 & 0.566 & -0.281 & 0.164 & -0.498 & $0.010^{* * *}$ \\
Income & -0.080 & 0.711 & 0.158 & 0.462 & 0.059 & 0.784 \\
Econ. Field of Study & 0.079 & 0.709 & -0.278 & 0.178 & -0.078 & 0.622 \\
\hline \hline
\end{tabular}

Note: Significance levels: $* * *=1 \%, * *=5 \%, *=10 \%$. Due to missing observations $\mathrm{N}=24$ for income; $\mathrm{N}=25$ for age and field of study and $\mathrm{N}=26$ for gender correlations. Field of study refers to economic disciplines against all other disciplines.

Table 12: Less Potential Gain Treatment: Descriptive Statistics of Differences between Interpersonal and Individual Risk Preferences

\begin{tabular}{cccccccc}
\hline \hline & \multicolumn{8}{c}{ Choice Problems } \\
\hline & Worse & \multicolumn{2}{c}{ Equal } & \multicolumn{2}{c}{ Better } \\
Min. & -10 & -3 & -2 & -1 & -5 & -4 \\
Mean & 0.62 & 0.65 & 1.35 & 0.62 & 0.92 & 0.42 \\
Max. & 5 & 7 & 7 & 5 & 7 & 7 \\
Std. deviation & 2.82 & 2.02 & 2.30 & 1.47 & 2.46 & 2.04 \\
\hline \% of obs. $<\mathbf{0}$ & 11.5 & 19.2 & 19.2 & 15.4 & 15.4 & 23.1 \\
\% of obs. $=\mathbf{0}$ & 46.2 & 46.2 & 30.8 & 46.2 & 34.6 & 38.5 \\
\% of obs. $>\mathbf{0}$ & 42.3 & 34.6 & 50.0 & 38.5 & 50.0 & 38.5 \\
\hline \hline
\end{tabular}


Figure 4: Less Potential Gain Treatment: Boxplots of Differences between Interpersonal and Individual Risk Preferences

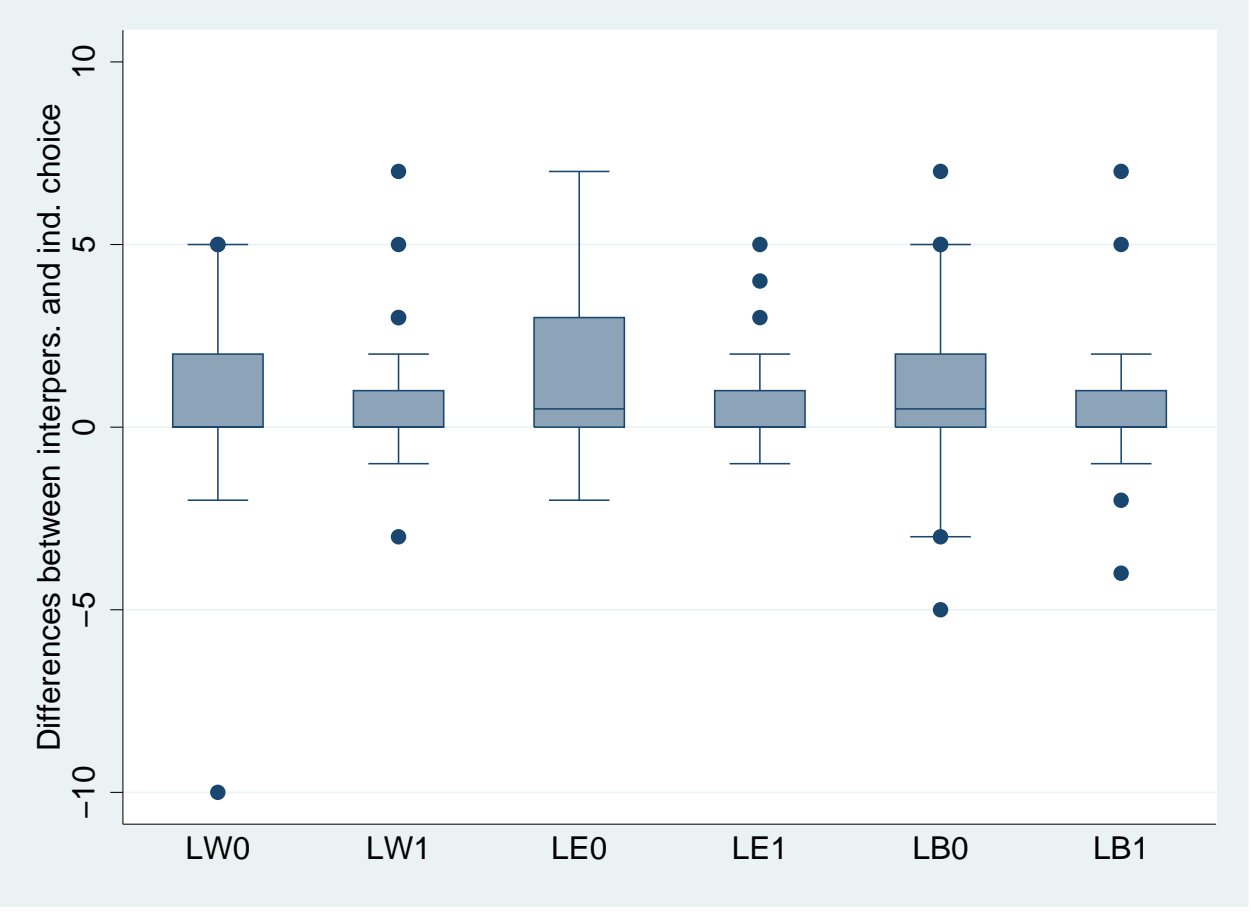

Table 13: Less Potential Gain Treatment: Two-sided Wilcoxon Signed Rank Test on Switching Points

\begin{tabular}{|c|c|c|c|}
\hline \multicolumn{4}{|c|}{ Comparisons between individual and interpersonal switching points } \\
\hline \multicolumn{2}{|c|}{ Choice Problems } & \multirow{2}{*}{$\begin{array}{c}\text { Test Statistic } \\
-1.801^{a}\end{array}$} & \multirow{2}{*}{$\begin{array}{r}\mathrm{p} \text {-value } \\
0.072 *\end{array}$} \\
\hline individual vs. & LW0 & & \\
\hline & LW1 & $-1.508^{a}$ & 0.131 \\
\hline & LE0 & $-2.577^{a}$ & $0.010 * * *$ \\
\hline & LE1 & $-1.998^{a}$ & $0.046 * *$ \\
\hline & LB0 & $-1.966^{a}$ & $0.049 * *$ \\
\hline & LB 1 & $-0.940^{a}$ & 0.347 \\
\hline
\end{tabular}

Note: Significance levels: $* * *=1 \%, * *=5 \%, *=10 \%, \mathrm{a}=$ positive ranks $>$ negative ranks, $\mathrm{b}=$ positive ranks $<$ negative ranks. 
Table 14: Less Potential Gain Treatment: Estimates of Random Effects Regressions on Switching Points

\begin{tabular}{|c|c|c|c|c|}
\hline Choice problems & MLE1 & MLE2 & TOBIT & OPROBIT \\
\hline \multirow[t]{2}{*}{ LW0 } & 0.6250 & 0.6154 & 0.7002 & $0.5343 *$ \\
\hline & $(0.4213)$ & $(0.3916)$ & $(0.4319)$ & $(0.2907)$ \\
\hline \multirow[t]{2}{*}{ LW1 } & 0.6250 & $0.6539 *$ & $0.7237 *$ & $0.5294 *$ \\
\hline & $(0.4213)$ & $(0.3916)$ & $(0.4310)$ & $(0.2909)$ \\
\hline \multirow[t]{2}{*}{ LE0 } & $1.2917 * * *$ & $1.3462 * * *$ & $1.5306 * * *$ & $1.0030 * * *$ \\
\hline & $(0.4213)$ & $(0.3916)$ & $(0.4348)$ & $(0.2981)$ \\
\hline \multirow[t]{2}{*}{ LE1 } & 0.6250 & 0.6154 & 0.6865 & 0.4607 \\
\hline & $(0.4213)$ & $(0.3916)$ & $(0.4310)$ & $(0.2893)$ \\
\hline \multirow[t]{2}{*}{ LB0 } & $0.9167 * *$ & $0.9231 * *$ & $1.0468 * *$ & $0.7080 * *$ \\
\hline & $(0.4213)$ & $(0.3916)$ & $(0.4325)$ & $(0.2933)$ \\
\hline \multirow[t]{2}{*}{ LB1 } & 0.3750 & 0.4231 & 0.4888 & 0.3379 \\
\hline & $(0.4213)$ & $(0.3916)$ & $(0.4308)$ & $(0.2898)$ \\
\hline \multirow[t]{2}{*}{ Age } & -0.0510 & & & \\
\hline & $(0.1100)$ & & & \\
\hline \multirow[t]{2}{*}{ Income } & 0.0012 & & & \\
\hline & $(0.0014)$ & & & \\
\hline \multirow[t]{2}{*}{ Econ. Field of Study } & -0.3749 & & & \\
\hline & $(0.7665)$ & & & \\
\hline \multirow[t]{2}{*}{ Gender $($ male $=1)$} & -0.3427 & & & \\
\hline & $(0.7164)$ & & & \\
\hline \multirow[t]{2}{*}{ Constant } & $7.3921 * * *$ & $6.5000 * * *$ & $6.4938 * * *$ & \\
\hline & $(2.4438)$ & $(0.3668)$ & $(0.39159$ & \\
\hline No. of observations & 168 & 182 & 182 & 182 \\
\hline $\mathrm{AIC}$ & 671.80 & 707.89 & 713.53 & 646.51 \\
\hline Log-likelihood & -322.8982 & -344.9433 & -347.7628 & -307.2531 \\
\hline
\end{tabular}

Note: Significance levels: $* * *=1 \%, * *=5 \%, *=10 \%$. The dependent variable is the switching point between option A and option B in all choice problems, coded as the last row, where the subject chose the safe choice A. Column 1 and 2 are random effect models with maximum likelihood estimator (MLE). Column 3 is a random effect tobit model and column 4 is an ordered probit model (estimated using Gllamm in Stata). A lower no. of observations in the first column is due to missing values for income. Field of study refers to economic disciplines against all other disciplines. 


\section{References}

Andersen, S., Harrison, G. W., Lau, M. I., Rutström, E. E., 2006. Elicitation using multiple price lists. Experimental Economics 9(4), 383-405.

Andreoni, J., 1989. Giving with impure altruism: Applications to charity and ricardian equivalence. Journal of Political Economy 97, 1447-1458.

Andreoni, J., 1990. Impure altruism and donations to public goods: A theory of warm-glow giving? Economic Journal 100(401), 464-77.

Andreoni, J., Erard, B., Feinstein, J., 1998. Tax compliance. Journal of Economic Literature 22, $333-335$.

Andreoni, J., Miller, J., 2002. Giving according to GARP: An experimental test of the rationality of altruism. Econometrica 70, 737-753.

Barr, A., Packard, T., 2002. Revealed preference and self insurance: Can we learn from the self employed in chile?, Policy Research Working Paper 2754, World Bank, Washington DC.

Beck, J., 1994. An experimental test of preferences for the distribution of income and individual risk aversion. Eastern Economic Journal 20(2), 131-145.

Becker, G. M., DeGroot, M. H., Marschak, J., 1964. Measuring utility by a single-response sequential method. Behavioral Science 9, 226-232.

Blinder, A. S., Choi, D. H., 1990. A shred of evidence on theories of wage stickiness. Quarterly Journal of Economics 105, 1003-1015.

Bolton, G., Ockenfels, A., 2008. Risk taking and social comparison - A comment on betrayal aversion: Evidence from Brazil, China, Oman, Switzerland, Turkey, and the United States, Working Paper Series in Economics, University of Cologne.

Bolton, G. E., 1991. A comparative model of bargaining: Theory and evidence. American Economic Review 81, 1096-1136.

Bolton, G. E., Ockenfels, A., 2000. A theory of equity, reciprocity and competition. American Economic Review 100, 166-193. 
Brennan, G., Güth, W., Gonzalez, L. G., Levati, M. V., 2005. Attitudes toward private and collective risks in individual and strategic choice situations, Discussion Paper 2005-22, Max Planck Institute of Economics, Strategic Interaction Group, Jena.

Carlsson, F., Daruvala, D., Johansson-Stenman, O., 2005. Are people inequality-averse, or just risk-averse? Economica 72(3), 375-396.

Charness, G., Jackson, M. O., 2007. The role of responsibility in strategic risk-taking, Working paper, University of California, Santa Barbara.

Charness, G., Rabin, M., 2002. Understanding social preferences with simple tests. Quarterly Journal of Economics 117, 817-869.

Daykin, A. R., Moffatt, P. G., 2002. Analyzing ordered responses: A review of the ordered probit model. Understanding Statistics 1(3), 157-166.

Fehr, E., Schmidt, K., 1999. A theory of fairness, competion and cooperation. Quarterly Journal of Economics 114, 817-868.

Fischbacher, U., 2007. z-tree: Zurich toolbox for ready-made economic experiments. Experimental Economics 10 (2), 171-178.

Forsythe, R. L., Horowitz, J., Savin, N. E., Sefton, M., 1994. Fairness in simple bargaining games. Games and Economic Behavior 6, 347-369.

Frohlich, N., Oppenheimer, J., Eavey, C., 1987. Laboratory results on rawl's distributive justice. British Journal of Political Science 17, 1-21.

Frohlich, N., Oppenheimer, J. A., 1990. Choosing justice in experimental democracies with production. American Political Science Review 84(2), 461-477.

Greiner, B., 2004. The online recruitment system ORSEE - A guide for the organization of experiments in economics. Discussion Papers on Strategic Interaction 2003-10, Max Planck Institute of Economics, Strategic Interaction Group.

Güth, W., Levati, M. V., Ploner, M., 2005. On the social dimension of time and risk preferences: An experimental study, Discussion Paper 2005-26, Max Planck Institute of Economics, Strategic Interaction Group, Jena.

Güth, W., Schmittberger, R., Schwarze, B., 1982. An experimental analysis of ultimatum bargaining. Journal of Economic Behavior and Organization 3, 367-88. 
Harrison, G. W., Rutström, E. E., 2008. Risk aversion in the laboratory. In: Cox, J. C., Harrison, G. W. (Eds.), Risk aversion in experiments. Bingley, UK: Emerald, Research in Experimental Economics Vol. 12.

Hausman, J. A., 1978. Specification tests in econometrics. Econometrica 46(6), 1251-1271.

Herne, K., Suojanen, M., 2004. The role of information in choices over income distributions. Journal of Conflict Resolution 48(2), 173-193.

Holt, C. A., Laury, S. K., 2005. Risk aversion and incentive effects: New data without order effects. American Economic Review 95(3), 902-912.

Kahneman, D., Knetsch, J. L., Thaler, R., 1986. Fairness as a constraint on profit seeking: Entitlements in the market. American Economic Review 76, 728-41.

Kirchsteiger, G., 1994. The role of envy in ultimatum games. Journal of Economic Behavior and Organization 25, 373-389.

Miller, L., Meyer, D. E., Lanzetta, J. T., 1969. Choice among equal expected value alternatives: Sequential effects of winning probability level on risk preferences. Journal of Experimental Psychology 79(3), 419-423.

Schubert, R., Brown, M., Gysler, M., Brachinger, H. W., 1999. Financial decision-making: Are women really more risk-averse? American Economic Review 89(2), 381-385.

Swope, K., Cadigan, J., Schmitt, P., Shupp, R. S., 2005. Social position and distributive justice: Experimental evidence, Working Papers 200505, Ball State University. 